\title{
Differences between Dorsal and Ventral Striatum in Drd1a Dopamine Receptor Coupling of Dopamine- and cAMP- Regulated Phosphoprotein-32 to Activation of Extracellular Signal-Regulated Kinase
}

\author{
Charles R. Gerfen, ${ }^{1}$ Ronald Paletzki, ${ }^{1}$ and Paul Worley ${ }^{2}$ \\ ${ }^{1}$ Laboratory of Systems Neuroscience, National Institute of Mental Health, Bethesda, Maryland 20892, and 2Department of Neuroscience, Johns Hopkins \\ University School of Medicine, Baltimore, Maryland 21205
}

\begin{abstract}
Dopamine receptor signaling exhibits prominent plasticity that is important for the pathogenesis of both addictive and movement disorders. Psychoactive stimulants that activate the dopamine $\mathrm{D}_{1}$ receptor (Drd1a) induce the rapid phosphorylation and activation of extracellular signal-regulated kinase $1 / 2$ (ERK1/2) in neurons of the nucleus accumbens and ventral striatum. This response is known to be dependent on the phosphatase inhibitor dopamine- and cAMP-regulated phosphoprotein-32 (DARPP-32) and appears critical for the sensitization of Drdla responses that contributes to addiction. Loss of dopamine input to the striatum, as in models of Parkinson's disease (PD), also results in a sensitization of responses to dopamine agonists that is manifest by increased activation of ERK1/2 in the dorsal striatum. Here, we test whether DARPP-32 is required for sensitization of Drdla responses in a PD model. In the normal dorsal striatum, there is minimal Drd1a-mediated activation of ERK1/2; however, in the PD model there is robust Drd1a-mediated activation of ERK1/2. In both wild-type and DARPP-32 knock-out mice, Drd1a robustly induces pERK1/2 throughout the dopamine-depleted striatum. These findings indicate that Drdla sensitization relevant for PD occurs by a novel mechanism that does not require DARPP-32.
\end{abstract}

Key words: amphetamine; basal ganglia; $\mathrm{D}_{1}$; dopamine; dopamine receptor; drug abuse; Parkinson's disease; striatum

\section{Introduction}

Among the functions ascribed to the striatum is the use of context- and reward-related information to guide learned behavior (Hikosaka et al., 2002; Schultz, 2002). Glutamatergic cortical inputs to the striatum carry context-dependent information about ongoing behavior (Ding and Hikosaka, 2006; Seger and Cincotta, 2006), and dopaminergic nigral inputs provide information about rewards (Schultz, 2002). Dopaminergic signals are thought to modulate corticostriatal synapses onto medium spiny projection neurons, and this plasticity is, in turn, thought to alter patterns of activity during learning (Schultz, 2002). Subversion of these processes is hypothesized to contribute importantly to addiction to psychostimulants (Nestler and Aghajanian, 1997; Greengard, 2001; Hyman et al., 2006), and movement disorders in Parkinson disease (PD) (Gerfen et al., 2002).

Activation of extracellular signal-regulated kinase $1 / 2$

Received March 23, 2007; revised Feb. 27, 2008; accepted May 20, 2008.

This work was supported by the National Institute of Mental Health Intramural Research Program (C.R.G.) and by National Institutes of Health Grant DA11742 (P.W.). DARPP-32 K0 mice were generously provided by Prof. Paul Greengard (The Rockefeller University, New York, NY). We acknowledge the excellent technical support of Ron Harbaugh, Michelle Tenace, and Alex Cummins. We also thank Steve Wise for providing statistical analysis of the cell count data.

Correspondence should be addressed to Charles R. Gerfen, Building 111, National Institutes of Health Animal Center, Dickerson, MD 20842. E-mail: gerfenc@mail.nih.gov.

DOI:10.1523/JNEUROSCI.3952-07.2008

Copyright $\odot 2008$ Society for Neuroscience $\quad$ 0270-6474/08/287113-08\$15.00/0
(ERK1/2) is critical for long-term changes in synaptic plasticity at glutamatergic synapses (Thomas and Huganir, 2004), and has been implicated in both psychostimulant addiction (Valjent et al., 2000, 2005) and in dopamine receptor agonist supersensitivity in PD models (Gerfen et al., 2002). Stimulation of corticostriatal glutamatergic inputs activate ERK1/2 in striatal neurons (Sgambato et al., 1998) through NMDA receptor coupling to $\mathrm{Ca}^{2+} /$ calmodulin signaling systems, which activate the MEK (mitogen-activated protein kinase kinase) responsible for phosphorylation of ERK1/2. Psychostimulants have been suggested to amplify such NMDA-mediated activation of ERK1/2 by activating the Drdla dopamine receptor (Valjent et al., 2005). In this model, Drd1a receptors coupled to PKA (protein kinase A) regulate dopamine receptor protein phosphatase inhibitor [dopamine- and cAMP-regulated phosphoprotein-32 (DARPP32)] (Greengard et al., 1999), whose inhibition of protein phosphatase 1, amplifies the activation of ERK1/2 (Valjent et al., 2005). This psychostimulant activation and associated behavioral effects are blocked by Drd1a antagonists, by NMDA antagonists, and by deletion of the genes encoding the Drdla receptor or DARPP-32 (Valjent et al., 2000, 2005). Together, these data support the model that DARPP-32 functions to integrate coincident Drdla- and NMDA-receptor-mediated signaling to evoke plasticity.

Although psychostimulants and Drd1a agonists robustly activate ERK1/2 in neurons of the nucleus accumbens and ventral 
striatum, they are only weakly effective in the normal dorsal striatum (Valjent et al., 2000). However, after lesions of the dopamine projection in a model of $\mathrm{PD}$, Drdla agonists produce a robust activation of ERK1/2 throughout the dorsal striatum (Gerfen et al., 2002). To assess whether this form of plasticity is also dependent on DARPP-32, we compared responses in wildtype and DARPP-32 knock-out (KO) mice.

\section{Materials and Methods}

Animals and treatments. All animal procedures used in this study were conducted in accordance with the Guide for the Care and Use of Laboratory Animals.

Animals used in this study included mice with a genetic deletion (knock-out) of the Drdla dopamine receptor (Drago et al., 1994) or the protein phosphatase inhibitor DARPP-32 (Fienberg et al., 1998). Both mice were on a C57BL/6 background and maintained with either homozygous or heterozygous breeding pairs. Wild-type control animals were age-matched from the breeding colonies used for the knock-out mice. For these studies, both male and females were used. The genotype of each animal was determined from tail clips using PCR with appropriate primer sequences.

Two different experimental paradigms were used, one in which psychostimulant drugs were administered to the animals, and the other in which Drdla agonists were administered to animals with unilateral lesions of the nigrostriatal dopamine system. To produce these lesions, mice of $\sim 25-35 \mathrm{~g}$ in weight were anesthetized with Nembutal and placed in a stereotaxic frame, and a unilateral lesion was produced by infusing 6-OHDA ( $8 \mu \mathrm{g}$ in $1 \mu \mathrm{l}$ ) into the substantia nigra. Animals were returned to their home cages, and food was supplemented with grapes for 2-3 weeks, during which the mice had unrestricted access to food and water.

Drug treatments used in these studies involved intraperitoneal administration of one of the following drugs: vehicle ( $0.9 \%$ saline), the psychostimulants D-amphetamine $(10 \mathrm{mg} / \mathrm{kg})$ or cocaine $(20$ or $30 \mathrm{mg} / \mathrm{kg})$, the Drdla agonist ( \pm )6-chloro-PB (6-chloro-7,8-dihyroxy-1-phenyl2,3,4,5-tetrahydro-1 H-3-bezazepine-hydrobromide) (SKF-81297) (item S-143; Sigma-Aldrich), or L-3,4-dihydroxyphenylanine methyl ester hydrochloride (L-DOPA) (20 mg/kg; item D1507; Sigma-Aldrich) with benserazide hydrochloride (12 mg/kg; item 7283; Sigma-Aldrich).

Fifteen minutes after drug treatment, the animals were asphyxiated with carbon dioxide and perfused transcardially with $4 \%$ formaldehyde in phosphate buffer, $\mathrm{pH}$ 7.4. Their brains were removed and processed for immunohistochemistry.

Histology. After perfusion, the brains were postfixed overnight at $4^{\circ} \mathrm{C}$ by immersion in the formaldehyde solution described above. The brains were then transferred to a $20 \%$ sucrose solution (in PBS, $\mathrm{pH} 7.4$ ) and were kept at $4^{\circ} \mathrm{C}$ until they sank. Brains were frozen and sectioned on a sliding microtome, and a series of $40 \mu \mathrm{m}$ coronal sections from the frontal pole through the midbrain were collected and stored at $4^{\circ} \mathrm{C}$ in PBS until processed for immunohistochemistry. Selected free-floating sections were incubated overnight in blocking solution $(0.2 \%$ Triton $\mathrm{X}-100,2 \%$ normal serum in PBS) containing primary antisera for tyrosine hydroxylase (TH) (1:250; Pel-Freez Biologicals), DARPP-32 (1: 4000; Millipore Bioscience Research Reagents), or phospho-ERK1/2 (1: 250; Cell Signaling Technology). The primary antibodies were visualized using the Vectastain $\mathrm{ABC}$ elite protocol (Vector Laboratories) and 3,3'-diaminobenzidine.

Microscopic digital imaging was used to analyze immunoreactivity (IR) in processed brain sections. When postimaging processing was performed, images taken from different animals were processed together to alter brightness, contrast, and color.

Western blots. Whole frozen brains stored at $-70^{\circ} \mathrm{C}$ were briefly warmed to $-20^{\circ} \mathrm{C}$ before striatal tissue samples were collected. Protein extracts were purified by sonication in $10 \times(\mathrm{v} / \mathrm{w}) 20 \mathrm{~mm}$ Tris- $\mathrm{HCl}, \mathrm{pH}$ 7.5, containing 2 mм EDTA, $20 \mathrm{~mm}$ glycerophosphate, $1 \mathrm{~mm} \mathrm{Na}_{3} \mathrm{VO}_{4}, 2$ $\mathrm{mm} \mathrm{NaF}$, and $1 \times$ Complete protease inhibitor mix (11 873580001 ; Roche), and then centrifuged at $15,000 \times g$ for $30 \mathrm{~min}$ at $4^{\circ} \mathrm{C}$. Supernatants were stored at $-70^{\circ} \mathrm{C}$. Protein concentrations were determined in triplicate using a BCA (bicinchoninic acid) assay kit (Pierce). Samples of
$18 \mu \mathrm{g}$ of protein were separated by SDS-PAGE using $4-12 \%$ gels and blotted onto $0.45 \mu \mathrm{m}$ pore size polyvinylidene difluoride using the $\mathrm{Nu}-$ PAge Novex (Invitrogen) electrophoresis system following the supplied protocols. Immunohistochemistry was performed using the phosphoErk1/2 (1:1000; 9101; Cell Signaling Technology), DARPP-32 (1:3000; AB1656; Millipore), or tyrosine hydroxylase (1:4000; P40101; Pel-Freez; Sigma-Aldrich) primary antibodies in $20 \mathrm{~mm}$ Tris- $\mathrm{HCl}, \mathrm{pH} 7.5$, containing $0.9 \%(\mathrm{w} / \mathrm{v}) \mathrm{NaCl}, 0.1 \%(\mathrm{v} / \mathrm{v})$ Tween 20 , and $5 \%(\mathrm{w} / \mathrm{v})$ nonfat dry milk. Antibody binding was detected using anti-rabbit-IgG-HRP secondary antibody (1:20,000; 7074; Cell Signaling Technology) and visualized by chemiluminescence (Supersignal; Pierce) and autoradiographic film (Kodak). Films were digitized and analyzed using NIH Image to determine the size of the band using the area under the plot profile for each band. If blots were reprobed, they were first stripped using Restore (Pierce) at $37^{\circ} \mathrm{C}$ for $30 \mathrm{~min}$, and then checked by incubating with secondary antibody at $1: 10,000$ for $1 \mathrm{~h}$ and visualized using chemiluminescence.

\section{Results \\ Requirement for Drd1a receptors and DARPP-32 for psychostimulant activation of ERK1/2}

Wild-type mice and mice with genetic deletions of the Drdla dopamine receptor or DARPP-32 were treated with the psychostimulants D-amphetamine (10 mg/kg, i.p.) or cocaine $(20 \mathrm{mg} /$ $\mathrm{kg}$, i.p.) and perfused 15 min later. For each treatment group, eight animals were used. Subsequently, the striatum was analyzed for neurons immunoreactive for phosphorylated ERK1/2 (phospho-ERK1/2). In wild-type mice, D-amphetamine treatment resulted in numerous neurons immunoreactive for phosphorylated ERK1/2, which were located in the nucleus accumbens (Fig. 1). In addition, there were some immunoreactive neurons in the medial region of the dorsal striatum. These neurons were most abundant adjacent to the ventricle, and their density decreased rapidly such that in the lateral region only a few scattered neurons were observed (Fig. 1). Knock-out of either Drdla or DARPP-32 resulted in a reduction of both the numbers and intensity of labeling of phospho-ERK1/2 in the nucleus accumbens compared with treated wild-type mice (Fig. 1). In both Drdla and DARPP-32 knock-out mice, phosphoERK1/2 immunoreactive neurons were present in the medial dorsal striatum. As in wild-type mice, in both of the knock-out mice there were very few phospho-ERK1/2-labeled neurons in the lateral dorsal striatum. Counts of amphetamine-induced phospho-ERK1/2-immunoreactive neurons in the different regions of the striatum show no significant difference in the lateral or medial dorsal striatum between wild-type or Drd1a or DARPP KO animals, whereas in the nucleus accumbens there is a $66 \%$ reduction in Drd $1 \mathrm{KO}$ and $61 \%$ percentage reduction in DARPP KO mice compared with wild type (Table 1).

Cocaine $(20$ or $30 \mathrm{mg} / \mathrm{kg}$ ) treatment produced phosphoERK1/2 responses similar to those produced by D-amphetamine $(10 \mathrm{mg} / \mathrm{kg})$ in terms of the distribution of phospho-ERK1/2immunoreactive neurons, although the level of immunoreactivity was qualitatively lower on a per cell basis with cocaine treatment (supplemental Fig. 1, available at www.jneurosci.org as supplemental material).

Transgenic mice in which enhanced green fluorescent protein (EGFP) is expressed under the control of the promoter for either Drd1a or Drd2 genes with bacterial artificial chromosome (BAC) constructs (Gong et al., 2003) were used to determine which striatal neuron types displayed phospho-ERK1/2 immunoreactivity after D-amphetamine treatment $(10 \mathrm{mg} /$ $\mathrm{kg}$ ). Double labeling using a red fluorochrome to visualize 


\section{d-amphetamine activation of ERK1/2 in D1- and DARPP-32 knockout mice}

wild type Drd1a KO
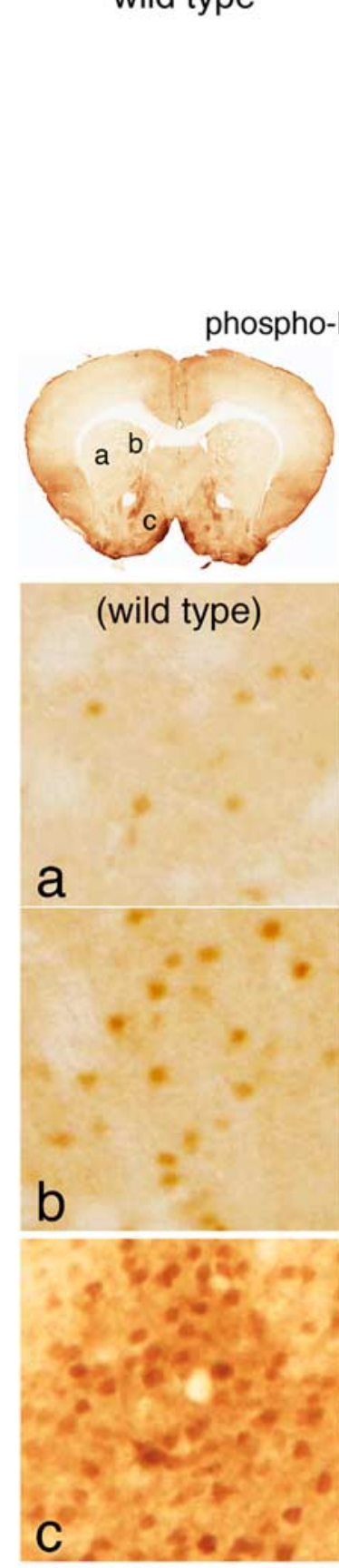

wild type

DARPP-32 KO
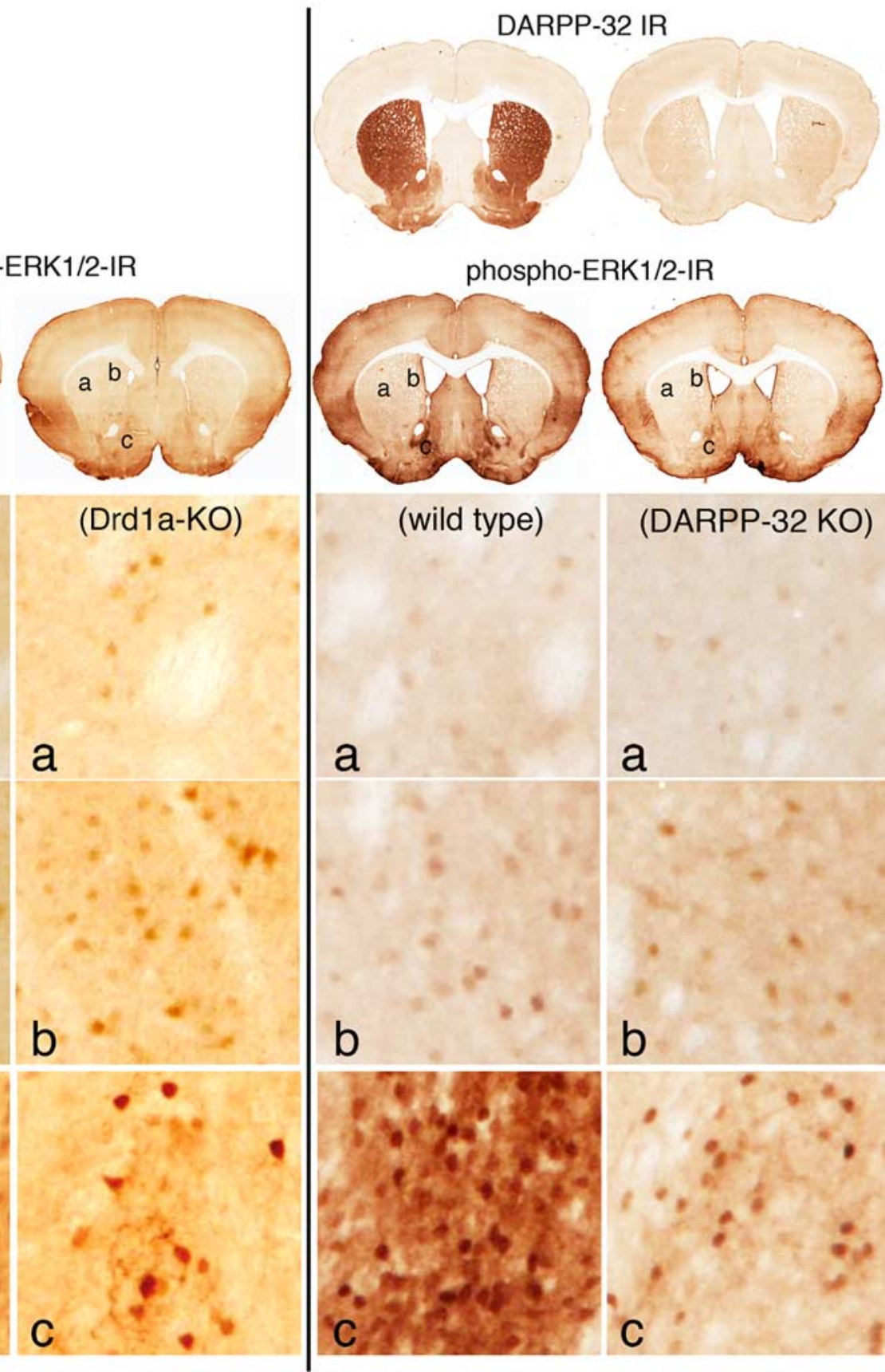

phospho-ERK1/2-IR
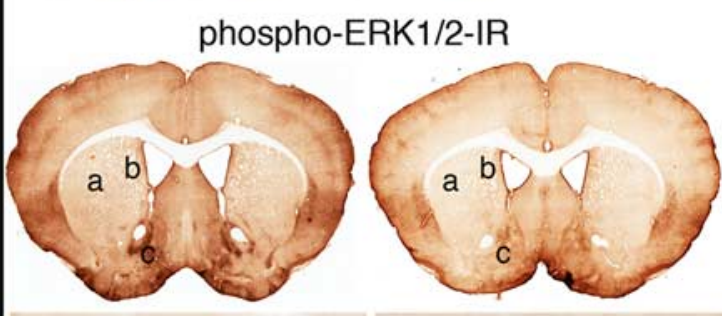

(wild type)

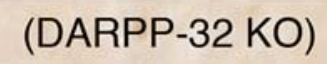

a

a
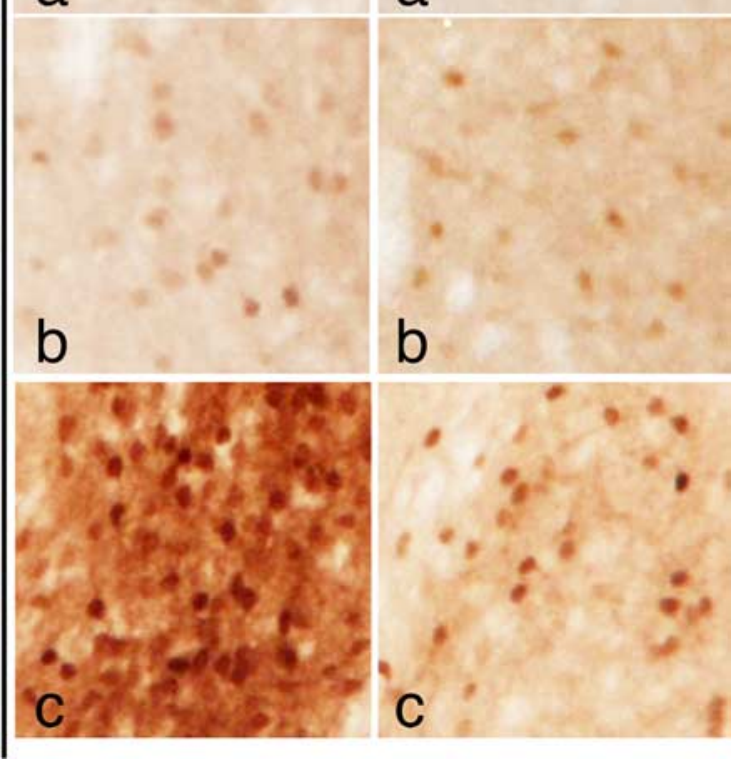

Figure 1. Psychostimulant-induced activation of ERK1/2 in Drd1a knock-out and DARPP-32 knock-out mice. Effects of D-amphetamine treatment (10 mg/kg) are compared between wild-type and Drd 1a KO mice and between wild-type and DARPP-32 K0 mice, in which DARPP-32-IR in the striatum is absent. Activation of ERK1/2 is indicated in coronal brain sections by neurons displaying immunoreactive phosphorylated ERK1/2 (phospho-ERK1/2-IR). In the dorsolateral striatum (a) and in the dorsomedial striatum $(\boldsymbol{b})$, the numbers of scattered neurons with D-amphetamine-induced immunoreactive phospho-ERK1/2 is similar in the wild-type and Drd1a K0 and DARPP-32 KO animals. In the shell of the nucleus accumbens (c), there are numerous D-amphetamine-induced phospho-ERK1/2-immunoreactive neurons in the wild-type mice, whereas in both the Drd1a K0 and DARPP- $32 \mathrm{~K} 0$ mice, the numbers of such neurons is markedly reduced. These data indicate that psychostimulant activation of ERK1/2 mediated by Drd1a and DARPP-32 is restricted to the nucleus accumbens.

phospho-ERK1/2 immunoreactivity and a green fluorochrome to visualize EGFP immunoreactivity was used to determine colocalization of the markers. The relative numbers of amphetamine-induced phospho-ERK1/2 immunoreactive neurons in different striatal regions was similar to that described above. In the Drd1a-BAC-EGFP mice, $>90 \%$ of striatal neurons displaying phospho-ERK1/2 colocalized with neurons expressing EGFP immunoreactivity, in all regions of the striatum (Fig. 2, Table 2). However, in the Drd2-BACEGFP mice, $<10 \%$ of neurons displaying phospho-ERK1/2 immunoreactivity coexpressed EGFP (Fig. 3, Table 2). 
Table 1. D -Amphetamine activation of ERK1/2 in striatal neurons in wild-type, Drd1a-K0, and DARPP-32-K0 mice

\begin{tabular}{|c|c|c|c|c|c|c|}
\hline Striatal region & Wild type & Drd1a K0 & $p$ value & Wild type & DARPP32 K0 & $p$ value \\
\hline Dorsal lateral & 5.2 & 6.0 & 0.268 & 4.7 & 5.5 & $0.268^{\mathrm{NS}}$ \\
\hline Dorsal medial & 19.7 & 21.3 & 0.322 & 18.7 & 21.0 & $0.294^{\mathrm{NS}}$ \\
\hline Accumbens & 55.8 & 19.3 & $0.0011^{* *}$ & 47.3 & 18.5 & $0.0011^{* *}$ \\
\hline
\end{tabular}

Counts of neurons showing phospho-ERK1/2 in different regions of the striatum and nucleus accumbens from animals in treatment groups described in this study. Treatment groups with $\mathrm{D}$-amphetamine (10 $\mathrm{mg} / \mathrm{kg}$, i.p.) included wild-type and Drd1a knock-out and DARPP-32 knock-out animals. Cell counts are the average from six animals per treatment group $(n=6)$ measured in a $100 \mu \mathrm{m}^{2}$ area in each region. Wilcoxon's rank sum test shows that there is only a significant reduction $(* * p<0.01)$ in amphetamine induction of phospho-ERK1/2 neurons in the nucleus accumbens in both Drd1a K0 and DARPP-32 K0 animals compared with wild type.

${ }^{* *} p<0.01<$ NS.

\section{Drd1a agonist activation of ERK1/2 in the intact and dopamine-depleted striatum}

Wild-type and DARPP-32 knock-out mice underwent unilateral 6-OHDA lesions of the nigrostriatal dopamine system. Three weeks after the lesion, they were treated with the full $\mathrm{D}_{1}$ receptor agonist SKF$81297(5 \mathrm{mg} / \mathrm{kg})$ and perfused $15 \mathrm{~min}$ later. For each treatment group, 8-10 animals were used. The striatum was then analyzed for neurons immunoreactive for phosphorylated ERK1/2. Unilateral degeneration of the nigrostriatal dopamine pathway was confirmed by the absence of $\mathrm{TH}$-immunoreactive neurons in the substantia nigra and in axon terminals in the striatum (Fig. 4). In the dopamine-intact striatum (contralateral to the lesion), phospho-ERK1/2 immunoreactive neurons were evident in the nucleus accumbens, but only scattered neurons were present in the dorsal striatum. This pattern of labeling resembles that seen with psychostimulant treatments in the dopamineintact striatum in the absence of 6-OHDA lesions, as described above. In the dopamine-depleted striatum, phosphoERK1/2-immunoreactive neurons were abundant and spread throughout both the dorsal striatum and the nucleus accumbens. This pattern of Drdla agonistinduced activation of ERK1/2 was identical in wild-type and DARPP-32 KO mice.

In a recent study, Santini et al. (2007) have implicated DARPP-32 activation of ERK $1 / 2$ as critical to the induction of L-DOPA-induced dyskinesias. To determine whether there was a difference between treatment with the Drdla agonist and L-DOPA, wild-type and DARPP-32 knockout mice with unilateral 6-OHDA lesions of the nigrostriatal dopamine system were treated with L-DOPA $(20 \mathrm{mg} / \mathrm{kg}$ L-DOPA with $12 \mathrm{mg} / \mathrm{kg}$ benserazide) for 1 or $10 \mathrm{~d}$. Results with L-DOPA treatment were identical with those with the Drd1a agonist treatment. In both wild-type and DARPP-32 knock-out animals, there was robust labeling of phospho-ERK1/2 immunoreactive neurons throughout the dopamine-depleted striatum (Fig. 4). Cell counts showed no significant difference between the numbers of phospho-ERK-immunoreactive neurons in the dopamine-depleted striatum between wild-type and DARPP-32 knock-out mice treated with either the Drdla-agonist or L-DOPA (Tables 3, 4).

The study by Santini et al. (2007) used Western immunoblot

\section{Amphetamine activation of ERK1/2 in Drd1a-striatal neurons}
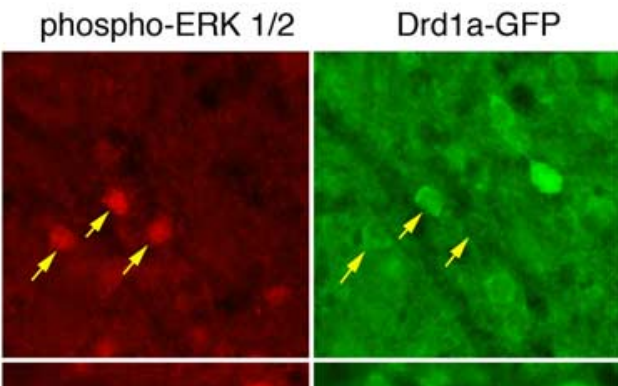

merge

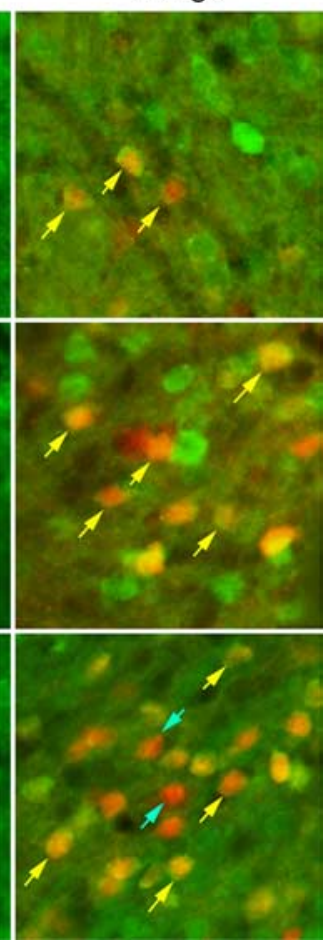

Figure 2. D-Amphetamine activation of ERK1/2 in Drd1a-expressing striatal neurons. Drd1a-BAC-EGFP transgenic mice were treated with D-amphetamine $(10 \mathrm{mg} / \mathrm{kg})$, and brain sections containing the striatum were processed for colocalization of many in the nucleus accumbens. In each region, nearly all phospho-ERK1/2-immunoreactive neurons colocalize with GFP (yellow GFP-IR negative (blue arrows) clearly evident as dark lacunas in the background of GFP fluorescence. These data indicate nearly all striatal neurons in which ERK1/2 is activated after D-amphetamine treatment express the Drd1a receptor.

analysis to determine the relative L-DOPA-induced activation of ERK1/2. We analyzed wild-type $(N=3)$ and DARPP-32 knockout $(N=3)$ mice with unilateral 6-ODHA lesions of the nigrostriatal dopamine pathway treated for $10 \mathrm{~d}$ with L-DOPA (20 $\mathrm{mg} / \mathrm{kg}$ L-DOPA with $12 \mathrm{mg} / \mathrm{kg}$ benserazide) by Western immunoblot. This analysis showed a robust activation of pERK2 in the DA-lesioned striatum in both wild-type and DARPP-32 knockout animals (Fig. 5). These immunoblot data are consistent with the immunohistochemical data described above.

To further examine the role of the Drdla dopamine receptor in activation of ERK1/2, Drd1a knock-out mice with unilateral lesions of the nigrostriatal dopamine system were treated with either the Drdla agonist (SKF-81297; $5 \mathrm{mg} / \mathrm{kg}$ ) or with L-DOPA (20 mg/kg with $12 \mathrm{mg} / \mathrm{kg}$ benserazide). Treatment with the Drd1a agonist produced no labeling of phospho-ERK1/2- 
Table 2. D -Amphetamine activation of ERK1/2 in Drd1a- and Drd2-expressing striatal neurons

\begin{tabular}{|c|c|c|c|c|c|c|}
\hline Striatal region & $\begin{array}{l}\text { pERK-immunoreactive/ } \\
\text { Drd1a-GFP }{ }^{+}\end{array}$ & $\begin{array}{l}\text { pERK-immunoreactive/ } \\
\text { Drd1a-GFP- }\end{array}$ & Drd1a-GFP ${ }^{+}(\%)$ & $\begin{array}{l}\text { pERK-immunoreactive/ } \\
\text { Drd1a-GFP }{ }^{+}\end{array}$ & $\begin{array}{l}\text { pERK-immunoreactive/ } \\
\text { Drd1a-GFP }{ }^{-}\end{array}$ & Drd2-GFP ${ }^{+}(\%)$ \\
\hline Dorsal lateral & 4.5 & 0.25 & 95 & 0.25 & 7.25 & 3.3 \\
\hline Dorsal medial & 12.5 & 1 & 93 & 1.0 & 15.75 & 6.0 \\
\hline Accumbens & 35.2 & 3.25 & 92 & 7 & 63.75 & 9.6 \\
\hline
\end{tabular}

Counts of phospho-ERK1/2-immunoreactive (pERK-immunoreactive) striatal neurons in different regions after D-amphetamine (10 mg/kg) in Drd1a-GFP and Drd2-GFP transgenic mice. Cell counts are the average numbers of pERK1/2immunoreactive cells that colocalize with GFP-IR in a $100 \mu \mathrm{m}^{2}$ area in each region. For each region, the percentage of pERK-immunoreactive cells is calculated by summing pERK-immunoreactive-positive cells, which are either GFP positive $\left(G^{+}\right.$) or GFP negative $\left(G F P{ }^{-}\right)$. Although the average number of pERK-immunoreactive cells varies from few in the dorsolateral striatum to many in the nucleus accumbens, $>90 \%$ colocalize with GFP in Drd $1 a-G F P$ mice, whereas $<10 \%$ colocalize with GFP in Drd2-GFP mice. These data indicate that $>90 \%$ of striatal neurons in which ERK1/2 is activated after $D$-amphetamine treatment express the Drd1a receptor.

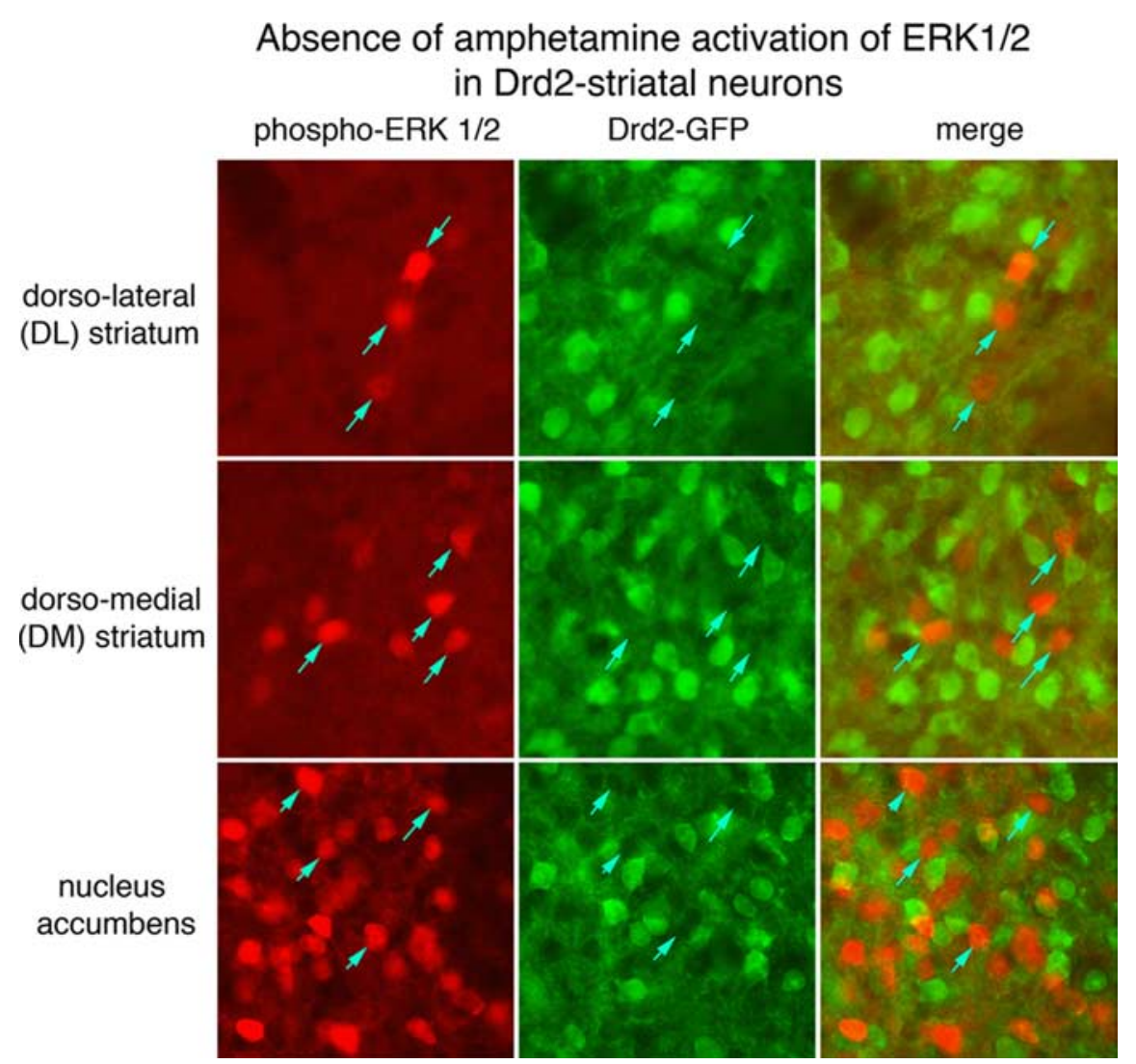

Figure 3. D-Amphetamine activates ERK1/2 in few Drd2-expressing striatal neurons. Drd2-BAC-EGFP transgenic mice were treated with D-amphetamine $(10 \mathrm{mg} / \mathrm{kg})$, and brain sections containing the striatum were processed for colocalization of phosphoERK1/2-IR (red fluorochrome) and GFP-IR (green fluorochrome). A $100 \mu \mathrm{m}^{2}$ area of the dorsolateral (DL), dorsomedial (DM), and nucleus accumbens is shown. The numbers of phospho-ERK1/2-immunoreactive neurons vary from few in the DL to many in the nucleus accumbens. In each region, nearly all phospho-ERK1/2-immunoreactive neurons do not express GFP, which is produced in Drd2-striatal neurons. These data indicate that very few striatal neurons in which ERK1/2 is activated after D-amphetamine treatment express the Drd2 receptor.

immunoreactive neurons in either the dopamine-intact or dopamine-depleted striatum (supplemental Fig. 2, available at www.jneurosci.org as supplemental material). This confirms that Drdla agonist activation of ERK1/2 in the dopamine-depleted striatum is dependent on the Drdla dopamine receptor. Treatment with L-DOPA resulted in no phospho-ERK1/2immunoreactive neurons in the dopamine-intact striatum and labeling of only scattered large neurons in the dopaminedepleted striatum (supplemental Fig. 2, available at www. jneurosci.org as supplemental material). The phospho-ERK1/2immunoreactive neurons colocalized ChAT (choline acetyl transferase) immunoreactivity (data not shown), indicating that these neurons are striatal cholinergic interneurons. These neurons express both the $\mathrm{D}_{2}$ and $\mathrm{D}_{5}$ dopamine receptors, which are likely responsible for their activation by L-DOPA treatment in the Drdla KO mice.

\section{Discussion}

The present study indicates that DARPP-32 is not required for a specific form of dopamine supersensitivity that is relevant for Parkinson's disease. Signaling events that couple dopamine Drdla activity to increases in phosphorylated ERK1/2 in neurons of the dorsal striatum undergo striking adaptations in response to loss of dopamine projections from the substantia nigra. In the normal dorsal striatum, selective $D_{1}$ agonists or cocaine result in modest increases in pERK $1 / 2$ that are restricted to a small subset of neurons. After denervation, $\mathrm{D}_{1}$ agonists evoke marked increases of pERK1/2 in a large population of neurons in the dorsal striatum. Whereas DARPP-32 is required for $\mathrm{D}_{1}$ agonist-induced increases of pERK1/2 in the ventral striatum and nucleus accumbens, the marked increase in pERK $1 / 2$ in the dorsal striatum consequent to loss of dopamine projections is identical in wid-type and DARPP-32 KO mice. This finding indicates that the adaptations that underlie denervationinduced Drdla supersensitivity in the dorsal striatum do not require DARPP-32.

Several lines of evidence support the notion that Drdla signaling that activates pERK1/2 is fundamentally different in the major populations of Drdla neurons in the ventral versus the dorsal striatum. In both Drdla knock-out and DARPP-32 knock-out mice, the acute effects of cocaine and amphetamine to induce pERK1/2 are significantly reduced in the nucleus accumbens (Valjent et al., 2005; this study). However, psychostimulant effects on induction of pERK1/2 are very modest in the dorsal striatum, and this pERK1/2 response persists in Drd1a knock-out and DARPP-32 knock-out animals. Moreover, even in the ventral striatum, there is a small population of neurons that show Drd1a-induced pERK1/2 in Drd1a or DARPP-32 KO mice. Accordingly, psychostimulant activation of ERK1/2 in the dorsolateral and dorsomedial striatum, as well as some of the activation in the nucleus accumbens, appears not to require Drdla receptors or DARPP-32. As with psychostimulants, either selective Drd1a agonist treatment or direct stimulation of the nigrostriatal dopamine pathway induces pERK1/2 in the nucleus accumbens, but does not produce activation in the dorsal striatum (Gerfen et al., 2002). In these same studies, either Drdla agonists or stimulation 


\section{Drd1a-agonist treatment}

wild type DARPP-32 KO

DARPP 32- IR
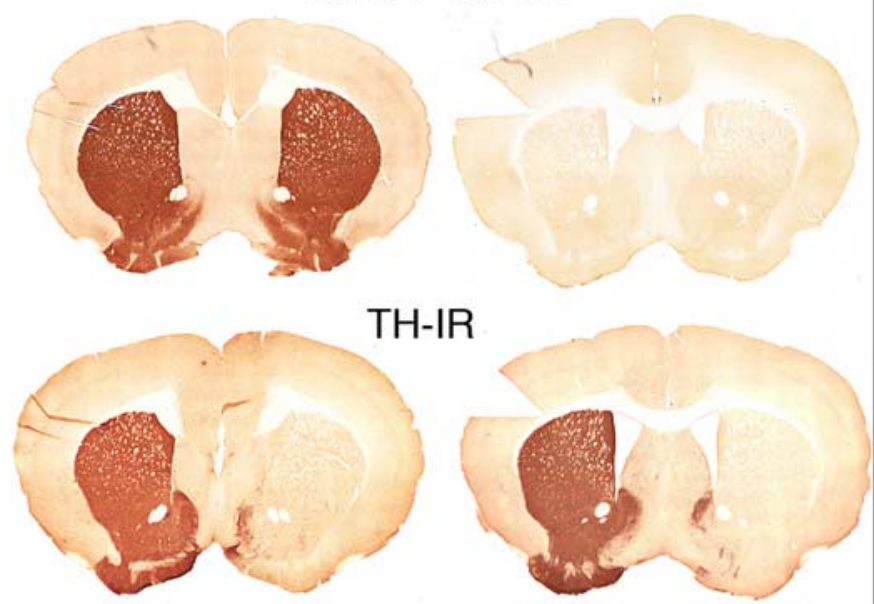

phospho-ERK1/2-IR
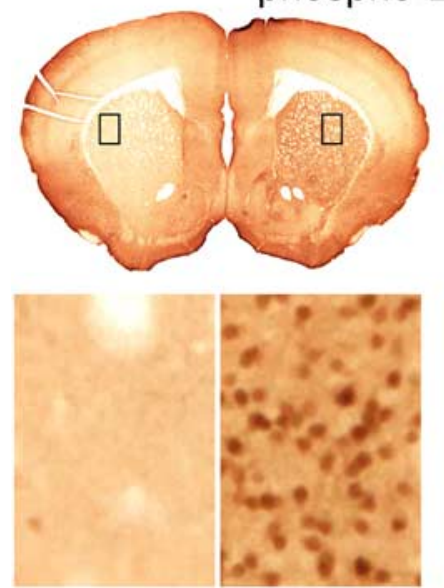

DA-intact

DA-depleted

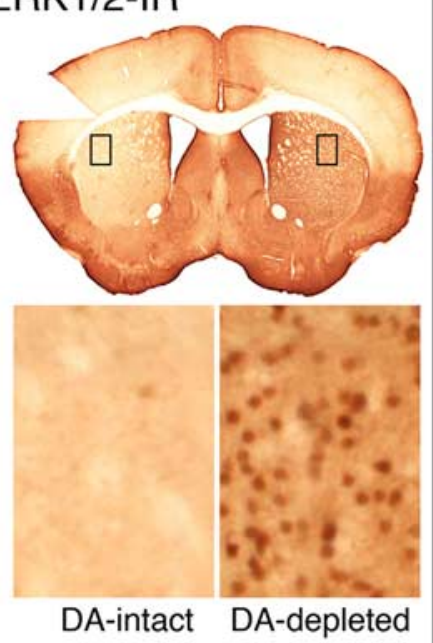

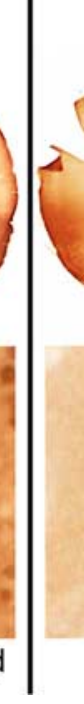

L-DOPA treatment wild type DARPP-32 KO

DARPP 32- IR
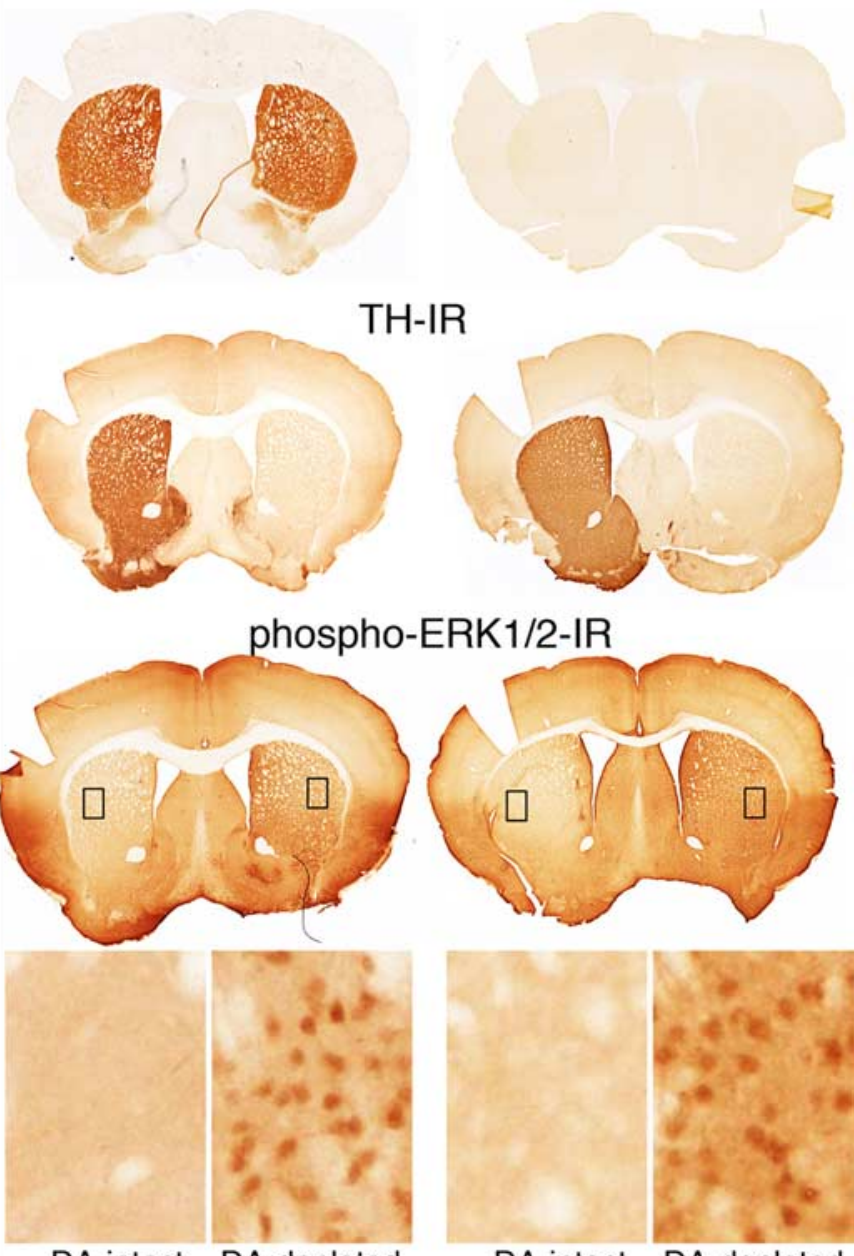

DA-intact DA-depleted

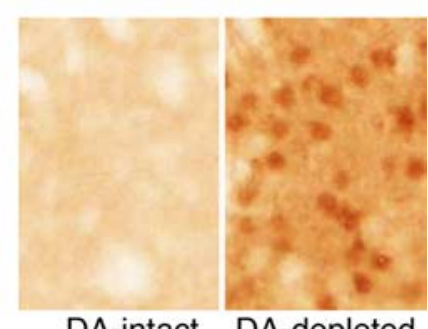

DA-intact DA-depleted

Figure 4. Drd1a-agonist or L-DOPA activation of ERK1/2 in the dopamine (DA)-depleted striatum does not involve DARPP-32. Comparison of coronal brain sections at the level of the rostral striatum from wild-type and DARPP-32 KO mice, with unilateral lesions of the nigrostriatal dopamine system and treated with a Drd1a agonist (SKF-81297; $5 \mathrm{mg} / \mathrm{kg} ; 1 \mathrm{~d}$ ) or L-D0PA (20 mg/kg with $12 \mathrm{mg} / \mathrm{kg}$ benserazide; $10 \mathrm{~d}$ ). DARPP-32-IR labels neurons in the striatum in wild-type mice, which are unlabeled in DARPP-32 K0 mice. Unilateral lesion of the nigrostriatal dopamine pathway in these animals is shown by the absence of TH-IR in the axonal terminals in the right striatum. Activation of ERK1/2 in response to either Drd1a agonist treatment (left images) or L-DOPA treatment (right images) is demonstrated by phospho-ERK1/2-IR throughout the dopamine-depleted striatum. High-power images from the dorsolateral striatum (inset boxes; $100 \mu \mathrm{m}$ wide) show few to no phospho-ERK1/2-immunoreactive neurons in the DA-intact striatum. In contrast, there are numerous phospho-ERK1/2-immunoreactive neurons in the DA-depleted striatum in both the wild-type and DARPP-32 K0 animals.

of the nigrostriatal dopamine system resulted in robust induction of immediate early genes in Drdla neurons throughout the ventral and dorsal striatum, confirming that neurons of the dorsal striatum are being stimulated.

Drdla signaling in the denervated dorsal striatum appears to be mechanistically most similar to that seen in the small population of Drdla neurons of the normal dorsal striatum that show Drd1a-induced increases in pERK1/2. This is inferred from the observations that Drd1a-pERK1/2 signaling in both populations of neurons is independent of DARPP-32. Importantly, this observation excludes the alternative possibility that the mechanism that transduces Drd1a signals to pERK1/2 in the lesioned dorsal striatum is the same as that used in the ventral striatum of normal animals. The molecular pathways that mediate this DARPP-32- independent response in both the intact and denervated dorsal striatum remain to be identified.

Activation of ERK1/2 has been implicated in plasticity in a variety of brain regions, including the cerebral cortex, amygdala, spinal cord, and nucleus accumbens, and contributes to several forms of learning and memory (Thomas and Huganir, 2004). What is common in these diverse regions is the dependence of activation of ERK1/2 on NMDA glutamatergic excitatory synaptic inputs. The normal function of dopamine in this process is to integrate convergent excitatory inputs, by regulating activation of ERK1/2 through a DARPP-32-mediated mechanism. Several features of Drd1a-mediated activation of ERK1/2 in the dopaminedepleted striatum are unique, including its independence of NMDA receptor function (Gerfen et al., 2002) and independence 
Table 3. Drd1a-agonist activation of ERK1/2 in striatal neurons in wild-type and DARPP-32 K0 mice

\begin{tabular}{|c|c|c|c|c|c|}
\hline \multirow[b]{2}{*}{ Striatal region } & \multicolumn{2}{|l|}{ Wild type } & \multicolumn{2}{|c|}{ DARPP-32 KO } & \multirow{2}{*}{$\begin{array}{l}\text { Comparison of wild-type and K0 } \\
\text { DA-depleted striatum } \\
p \text { value }\end{array}$} \\
\hline & DA-intact & DA-depleted & DA-intact & DA-depleted & \\
\hline Dorsal lateral & 3.5 & 46.5 & 4.2 & 50.5 & $0.220^{\mathrm{NS}}$ \\
\hline Dorsal medial & 13.5 & 49.2 & 10.0 & 56.2 & $0.078^{\mathrm{NS}}$ \\
\hline Accumbens & 24.7 & 50.8 & 20.3 & 49.2 & $0.409^{\mathrm{NS}}$ \\
\hline
\end{tabular}

Treatment groups receiving Drd1a agonist (SKF-81297; $5 \mathrm{mg} / \mathrm{kg}$ ) had unilateral 6-OHDA lesions of the nigrostriatal dopamine pathway. Phospho-ERK1/2-immunoreactive neurons were counted in the DA-intact and DA-depleted striatum in wild-type and DARPP-32 knock-out animals. Cell counts are the average from six animals per treatment group $(n=5)$ measured in a $100 \mu m^{2}$ area in each region. Wilcoxon's rank sum test was performed to compare the DA-depleted striatum from the wild-type and DARPP-32 K0 animals. There was no significant difference (NS, $p>0.01$ ) between wild-type and DARPP-32 K0 animals in the numbers of neurons displaying Drd1a agonist-activated ERK1/2 in the DA-depleted striatum.

${ }^{* *} p<0.01<$ NS.

Table 4. L-DOPA activation of ERK1/2 in striatal neurons in wild-type and DARPP-32 KO mice

\begin{tabular}{|c|c|c|c|c|c|}
\hline \multirow[b]{2}{*}{ Striatal region } & \multicolumn{2}{|l|}{ Wild type } & \multicolumn{2}{|c|}{ DARPP-32 K0 } & \multirow{2}{*}{$\begin{array}{l}\text { Comparison of wild-type and KO } \\
\text { DA-depleted striatum } \\
p \text { value }\end{array}$} \\
\hline & DA-intact & DA-depleted & DA-intact & DA-depleted & \\
\hline Dorsal lateral & 6.6 & 51.4 & 3 & 58.2 & $0.183^{\text {NS }}$ \\
\hline Dorsal medial & 16.8 & 43.8 & 7.4 & 50.8 & $0.111^{\mathrm{NS}}$ \\
\hline Accumbens & 27.8 & 39.6 & 20.0 & 46.0 & $0.21^{\mathrm{NS}}$ \\
\hline
\end{tabular}

Treatment groups receiving L -DOPA (20 mg/kg plus $12 \mathrm{mg} / \mathrm{kg}$ benserazide for $10 \mathrm{~d}$ ) had unilateral 6-OHDA lesions of the nigrostriatal dopamine pathway. Phospho-ERK1/2-immunoreactive neurons were counted in the DA-intact and DA-depleted striatum in wild-type and DARPP-32 knock-out animals. Cell counts are the average from five animals per treatment group $(n=5)$ measured in a $100 \mu \mathrm{m}^{2}$ area in each region. Wilcoxon's rank sum test was performed to compare the DA-depleted striatum from the wild-type and DARPP-32 K0 animals. There was no significant difference (NS, $p>0.01$ ) between wild-type and DARPP-32 K0 animals in the numbers of neurons displaying L-DOPA-activated ERK1/2 in the DA-depleted striatum.

${ }^{* *} p<0.01<$ NS.

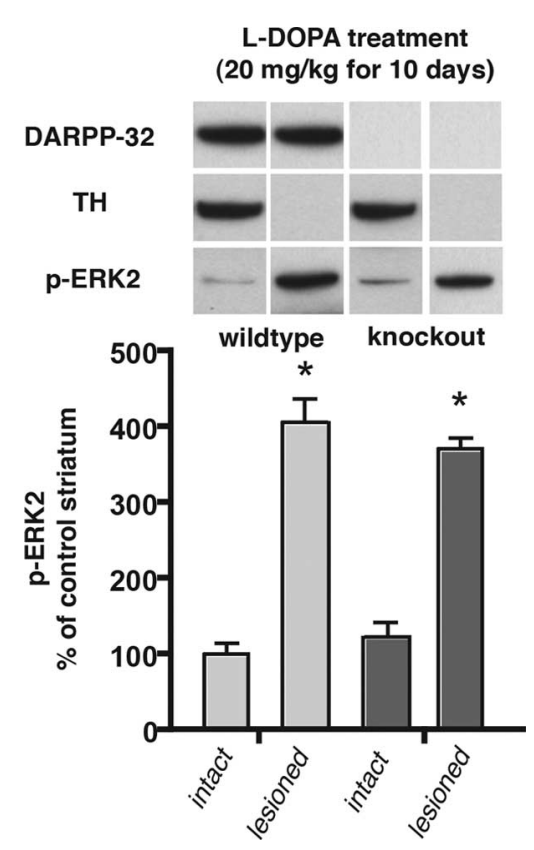

Figure 5. L-DOPA activation of ERK2 in the dopamine-depleted striatum is not significantly reduced in DARPP-32 knock-out mice. Western immunoblot data from wild-type $(n=7)$ and DARPP-32 knock-out $(n=5$ ) animals with unilateral 6-OHDA lesions of the nigrostriatal dopamine pathway treated for $10 \mathrm{~d}$ with L-DOPA ( $20 \mathrm{mg} / \mathrm{kg}$ with $12 \mathrm{mg} / \mathrm{kg}$ benserazide). Animals were killed 30 min after the last injection and the dissected striatum were processed by Western blotting to determine levels of immunoreactivity for DARPP-32, TH, and phosphorylated ERK2 (pERK2). There is robust activation of pERK2 in the dopamine-depleted compared with the intact striatum of both wild-type and DARPP32 KO animals ( ${ }^{*} p<0.05$ ). However, there is no significant difference in the activation of pERK2 in the dopamine-lesioned striatum comparing wild-type and DARPP-32 KO animals (percentage above intact control: wild type, 406\%; K0, 371\%; $p>0.05)$.

of DARPP-32 (this study). The absence of NMDA and DARPP-32 regulatory controls underscores the unique features of signaling in dorsal striatal neurons and anticipates novel forms of synaptic plasticity.
Adaptations of Drdla signaling are likely to contribute to the pathogenesis of PD. Neurons that express Drdla in the dorsal striatum are part of the "direct pathway" that projects to the substantia nigra pars reticula and are important for voluntary motor responses. Loss of dopamine input alters the function of direct-pathway neurons, and this is linked to changes in motor behavior observed in PD. Because these neurons normally function to disinhibit (activate) motor circuits, their enhanced Drd1a-pERK1/2 signaling may represent a homeostatic adaptation to increase this drive, and as such may be linked to increased locomotor activity in response to $\mathrm{D}_{1}$ agonists. We previously proposed that these adaptations contribute to altered motor behaviors, including dyskinesias or "on-off syndrome," in PD patients who have been chronically treated with dopamimetic agonists (Gerfen et al., 2002). Consistent with this proposal, two recent studies (Santini et al., 2007; Westin et al., 2007) have demonstrated the involvement of activation of ERK1/2 in the development of L-DOPA-induced dyskinesia in rodent models of PD. The study by Santini et al. (2007) also proposed that DARPP-32 is critical in mediating L-DOPA activation of ERK $1 / 2$ because there is a significant reduction in ERK1/2 activation in DARPP-32 KO mice compared with wild type as determined with Western blot analysis. In the current study, using the same L-DOPA treatment paradigm, we report that there is no significant difference between wild-type and DARPP-32 KO mice in the numbers of striatal neurons displaying phospho-ERK1/2 immunoreactivity nor in the level of phospho-ERK2 analyzed with Western blots in the dopamine-depleted striatum. Given our finding of robust L-DOPA-induced activation of ERK1/2 in the majority of Drd1astriatal neurons in DARPP-32 KO mice, we conclude that DARPP-32 is not critical to such activation. However, given the demonstrated critical role that DARPP-32 has in mediating a wide variety of signal transduction mechanisms, it is possible that DARPP-32 may be involved in mechanisms underlying altered synaptic plasticity responsible for L-DOPA-induced dyskinesias.

In summary, two major conclusions may be drawn from the present study. First, the mechanism involving DARPP-32 regu- 
lation of Drd1a-mediated activation of ERK1/2 is regionally restricted within the striatum to the nucleus accumbens, a part of the ventral striatum. Second, the Drdla-mediated activation of ERK1/2 in the dopamine-depleted dorsal striatum does not involve an "amplification" of the DARPP-32-mediated regulation of Drd 1 signaling that occurs in the nucleus accumbens. Rather, it represents a novel signaling pathway that is most similar to Drdla signaling seen in a small population of dorsal striatal neurons in intact animals that it is independent of DARPP-32. Together, these results demonstrate the existence of regionally distinct cellular and molecular mechanisms within the striatum that mediate Drd1 signaling.

\section{References}

Ding L, Hikosaka O (2006) Comparison of reward modulation in the frontal eye field and caudate of the macaque. J Neurosci 26:6695-6703.

Drago J, Gerfen CR, Lachowitz JE, Steiner H, Hollon TR, Love PE, Ooi GT, Grinberg A, Lee EJ, Huang SP, Bartlett PF, Jose PA, Sibley DR, Westphal $\mathrm{H}$ (1994) Altered striatal function in a mutant mouse lacking D1A dopamine receptors. Proc Natl Acad Sci U S A 91:12564-12568.

Fienberg AA, Hiroi N, Mermelstein PG, Song W, Snyder GL, Nishi A, Cheramy A, O'Callaghan JP, Miller DB, Cole DG, Corbett R, Haile CN, Cooper DC, Onn SP, Grace AA, Ouimet CC, White FJ, Hyman SE, Surmeier DJ, Girault J, et al. (1998) DARPP-32: regulator of the efficacy of dopaminergic neurotransmission. Science 281:838-842.

Gerfen CR, Miyachi S, Paletzki R, Brown P (2002) D dopamine receptor supersensitivity in the dopamine-depleted striatum results from a switch in the regulation of ERK1/2/MAP kinase. J Neurosci 22:5042-5054.

Gong S, Zheng C, Doughty ML, Losos K, Didkovsky N, Schambra UB, Nowak NJ, Joyner A, Leblanc G, Hatten ME, Heintz N (2003) A gene expression atlas of the central nervous system based on bacterial artificial chromosomes. Nature 425:917-925.

Greengard P (2001) The neurobiology of slow synaptic transmission. Science 294:1024-1030.
Greengard P, Allen PB, Nairn AC (1999) Beyond the dopamine receptor: the DARPP-32/protein phosphatase-1 cascade. Neuron 23:435-447.

Hikosaka O, Nakamura K, Sakai K, Nakahara H (2002) Central mechanisms of motor skill learning. Curr Opin Neurobiol 12:217-222.

Hyman SE, Malenka RC, Nestler EJ (2006) Neural mechanisms of addiction: the role of reward-related learning and memory. Annu Rev Neurosci 29:565-598.

Nestler EJ, Aghajanian GK (1997) Molecular and cellular basis of addiction. Science 278:58-63.

Santini E, Valjent E, Usiello A, Carta M, Borgkvist A, Girault JA, Herve D, Greengard P, Fisone G (2007) Critical involvement of cAMP/ DARPP-32 and extracellular signal-regulated protein kinase signaling in L-DOPA-induced dyskinesia. J Neurosci 6995-7005.

Schultz W (2002) Getting formal with dopamine and reward. Neuron 36:241-263.

Seger CA, Cincotta CM (2006) Dynamics of frontal, striatal, and hippocampal systems during rule learning. Cereb Cortex 16:1546-1555.

Sgambato V, Pagès C, Rogard M, Besson MJ, Caboche J (1998) Extracellular signal-regulated kinase (ERK) controls immediate early gene induction on corticostriatal stimulation. J Neurosci 18:8814-8825.

Thomas GM, Huganir RL (2004) MAPK cascade signalling and synaptic plasticity. Nat Rev Neurosci 5:173-183.

Valjent E, Corvol JC, Pages C, Besson MJ, Maldonado R, Caboche J (2000) Involvement of the extracellular signal-regulated kinase cascade for cocaine-rewarding properties. J Neurosci 20:8701-8709.

Valjent E, Pascoli V, Svenningsson P, Paul S, Enslen H, Corvol JC, Stipanovich A, Caboche J, Lombroso PJ, Nairn AC, Greengard P, Hervé D, Girault JA (2005) Regulation of a protein phosphatase cascade allows convergent dopamine and glutamate signals to activate ERK in the striatum. Proc Natl Acad Sci U S A 102:491-496.

Westin JE, Vercammen L, Strome EM, Konradi C, Cenci MA (2007) Spatiotemporal pattern of striatal ERK1/2 phosphorylation in a rat model of L-DOPA-induced dyskinesia and the role of dopamine D1 receptors. Biol Psychiatry 62:800-810. 